\title{
INTERACTION BETWEEN STORM WATER CONDUIT AND SURFACE FLOW FOR URBAN FLOOD INUNDATION MODELLING
}

\author{
J. HAKIEL \& M. SZYDEOWSKI \\ Department of Hydraulic Engineering, Gdańsk University of Technology, Poland.
}

\begin{abstract}
Rapid development of urban areas always comes with great side effects. One of them is the occurrence of urban floods. Growth of impervious surfaces in cities leads to increasing run-off values. This together with difficulties connected with sewage modernization in cities marks urban inundations as being one of the most important issues concerning urban water. Accurate prediction of a phenomenon is difficult as it is highly dependent on local conditions and the quality of available data about them. A most recent approach to modelling urban flooding involves a detailed description of the interaction between storm water sewage flow modelling and surface flow modelling. In this paper we will describe a numerical model of urban inundation that is being used to analyse the phenomenon, which consists of 1D storm water flow model (explicit McCormack scheme) and 1D surface flow model (diffusive wave). But before that laboratory tests describing the interaction between used models will be introduced. We will try to evaluate how different surface flow conditions affect interaction and find out if there is an easy way to implement it in coupled numerical modelling of large-scale urban areas inundations. Because tests are still being conducted and further investigation of phenomenon is being done, the conclusions are only preliminary and should be treated as a guideline for future work.

Keywords: dual drainage models, exchange discharge, storm water sewage flow, surface flow, urban floods.
\end{abstract}

\section{INTRODUCTION}

Flooding in urban areas can be caused by many factors. These can be, for example, overflowing rivers or channels passing through cities or, in most cases, insufficient capacity of the storm water sewage system. Most often, rainwater sewage in urban areas consist of three parts, which are underground sewage (pipes), surface sewage (gutter, drain, canal etc.) and interaction structures which are inlets or manholes. Inundations that are connected to storm water sewage systems come from excessive rainfall that can not be drained by a sewage system. This results in rainwater conduits surcharge and excessive surface flow. [1-3]. Although both sewage flow and surface flow can be done with well-known tools (numerical schemes) [4-6], the model as a whole is really difficult to validate. That uncertainty exists mainly due to flow exchange formulas between sewage and surface [7]. In most cases, that phenomenon is highly connected to the type of structures in storm water sewage. Various inlet types give substantially different exchange flow values, which indicates how our model is related to reality. Therefore, accurate validation of interaction formulas is essential.

There are a couple of approaches that are used in calculating the interaction between surface and sewage in urban areas inundation modelling. One of them is the usage of weir and 
orifice equation [2]. These equations can give us exchange flow information both for inflow into sewage and overflow when surcharge occurs. However, the main problem with this approach is the fact that weir and orifice formulas were derived for simple hydraulic structures, not inlets. The biggest differences here are (1) the inflow area shape which is significantly more complex and (2) surface flow conditions wherein inundations in urban areas greatly differ from the situations for which weir and orifice formulas should be applied. To expand the use range of the mentioned equation one can diversify the coefficient according to used structures [7]. A similar approach can consist of calculating limited exchange discharges for parts of our structure, which can correspond for example to inflow through grate, flow in pipe connecting intake device and sewage and outflow from that pipe into a rainwater underground conduit [8].

Other approaches to calculating interaction between storm water conduit and surface can be based on empirical formulas derived for specific intake devices[9]. These give us the possibility to verify the exchange flow with limitation to the range of our experiments.

In this paper, the experimental stand used for flow exchange formulas verification and derivation at Gdańsk university of Technology will be described first. Preliminary results of tests and the proposed direction of research and approach to interaction of surface and sewage flow will be detailed. In the latter part of the paper, a mathematical model which will be used for modelling will be outlined. The paper sums up with a section on the conclusions that can be drawn from the results with a short highlight on future research objectives.

\section{EXPERIMENTS}

\subsection{Test Stand}

Test stand which is being used for storm water sewage flow and surface flow interaction is located in Gdańsk University of Technology in the Hydraulic laboratory of the Hydraulic Engineering Department, Figs 1 and 2).

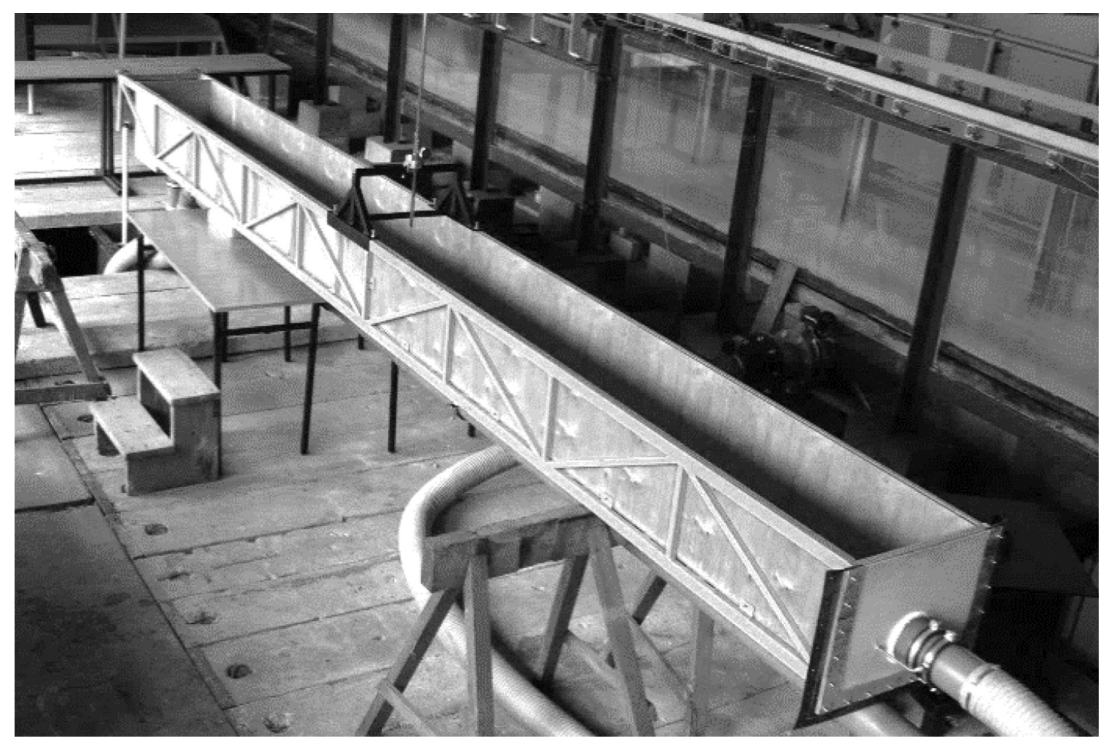

Figure 1: Photograph of laboratory stand. 
Plan

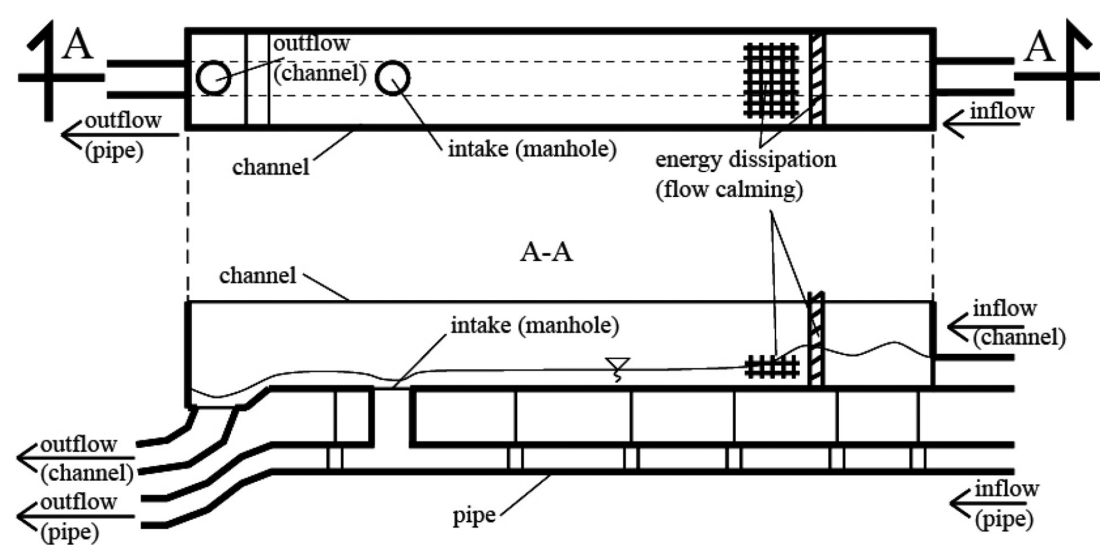

Figure 2: Scheme of laboratory stand.

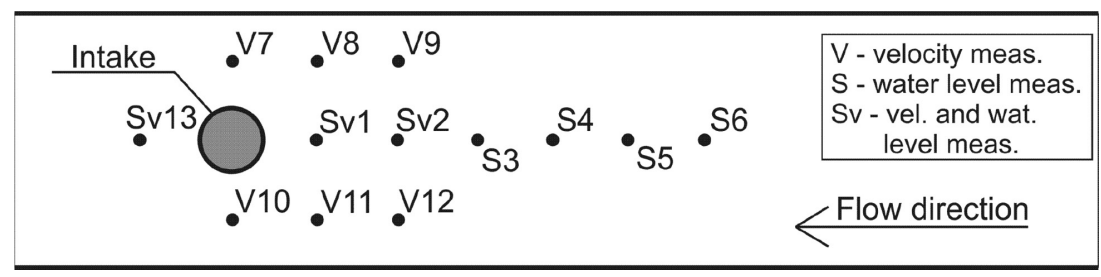

Figure 3: Measurement points placement.

Stand consists of a channel that represents a surface that is $5.5 \mathrm{~m}$ long and $0.4 \mathrm{~m}$ wide and mounted underneath it is a $100 \mathrm{~mm}$ diameter pipe. These two parts are connected through a tee joint of the same diameter as that of a pipe simulating manhole. The interaction point, which is located $1 \mathrm{~m}$ before the channel outflow, can be adjusted by fittings simulating different inlet structures. The whole stand has an adjustable slope which is the same for the channel and pipe. The inflow is possible either from surface or into sewage. In the initial part of the channel the flow is stabilised. Outflow from both pipes is independent.

Measurement of water level in the channel is possible along all of the channel by a movable rack. Outflow discharges can be measured independently for both surface and pipe. Due to the fact that the stand can be supplied only separately into the channel or pipe, the inflow value can be adopted as being a sum of both outflows. In addition, flow velocities were measured in 9 points from which 6 were located in front of the interaction point 2 on its sides and one directly behind it, Fig. 3.

\subsection{Experiment scenarios and measurements}

The main part of the measurement was made for steady flow conditions with inflow only into the surface part of test stand. The aim of the experiments was to evaluate how accurate weir and orifice equations are in describing inflow into inlets with free flow conditions for various surface slopes and what comes with different surface flow velocities for the same surface water levels. Measurements were made for 7 surface slopes varying from $0 \%$ to $3 \%$. For each one, 6-8 flow values were tested which ranged from $0.3 \mathrm{dm}^{3} / \mathrm{s}$ to $21.88 \mathrm{dm}^{3} / \mathrm{s}$, Table 1 . 
Table 1: Flow and surface slope characteristics in experiment scenarios.

\begin{tabular}{llll}
\hline \multicolumn{2}{l}{ Scenario $\mathrm{nr}$ Surface slope $(\%)$} & Number of discharges & Range of inflow discharges $\left(\mathrm{dm}^{3} / \mathrm{s}\right)$ \\
\hline 1 & 0.1 & 8 & $0.34-20.10$ \\
2 & 0.2 & 8 & $0.34-21.38$ \\
3 & 0.4 & 8 & $0.30-21.88$ \\
4 & 0.6 & 6 & $0.41-17.14$ \\
5 & 1.0 & 6 & $0.49-18.59$ \\
6 & 1.5 & 6 & $0.67-19.32$ \\
7 & 3.0 & 5 & $1.13-17.53$ \\
\hline
\end{tabular}

For each scenario a full set of data was measured, which consisted of outflow values both from surface and sewage, velocities at all 9 points and water levels at the same points and every next $10 \mathrm{~cm}$ till surface flow stabilization structure. Most important measurements that are used in further analysis are outflow values and water level and velocity $5 \mathrm{~cm}$ above interaction structure which will be used for exchange discharge calculation; points at which those values are measured is shown in Fig. 3 (SV1). In the next section, exchange model will be presented. Measurement results will be used to analyse and verify shown equations and, subsequently, proposition of implementation of surface flow conditions into the model will be described.

\section{EXCHANGE MODEL}

\subsection{Basic weir, orifice equations}

Key factor to correct modelling of urban areas inundation are exchange formulas. The approach described and analysed in papers is based on weir and orifice equations [Chen 2007]. Interaction discharges are calculated according to the difference in water levels on surface and in rain water sewage. Depending on the direction of flow, upstream water level is set as $h_{U}=\max \left\{h_{m h}, h_{s}\right\}$ and downstream water level as $h_{D}=\min \left\{h_{m h}, h_{s}\right\}$, where $h_{m h}$ stands for hydraulic head at manhole and $h_{s}$ is surface water elevation; both values must have a common reference level. Choice of formula from described equations is based on the relation between listed water levels and crest elevation $z_{\text {crest }}$, Fig. 4.

First formula is adapted to a situation when the crest elevation $\left(z_{\text {crest }}\right)$ is between upstream water level $\left(h_{U}\right)$ and downstream water level $\left(h_{D}\right)$, Fig. 4 , which can be written as:

$$
Q=\operatorname{sign}\left[h_{m h}-h_{2 d}\right] c_{w} w \sqrt{2 g}\left(h_{U}-z_{\text {crest }}\right)^{3 / 2} .
$$

where $Q$ stands for the interaction discharge $\left[\mathrm{m}^{3} / \mathrm{s}\right], c_{w}$ is the weir discharge coefficient, $w$ is the weir crest width and $g$ is the acceleration due to gravity.

When both upstream water level $\left(h_{U}\right)$ and downstream water level $\left(h_{D}\right)$ are above the crest elevation $\left(z_{\text {crest }}\right)$, Fig. 4 , and upstream water level above the crest $\left(h_{U}-z_{\text {crest }}\right)$ is less than $A_{m h} / w$, where $A_{m h}$ stands for manhole area submerged weir linkage should be used:

$$
Q=\operatorname{sign}\left[h_{m h}-h_{2 d}\right] c_{w} w \sqrt{2 g}\left(h_{U}-z_{\text {crest }}\right)\left(h_{U}-h_{D}\right)^{1 / 2} .
$$




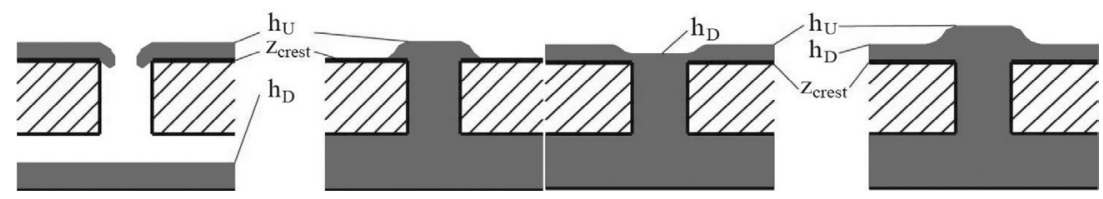

Figure 4: Scheme of conditions for free weir formula (left) and submerged weir formula (right).

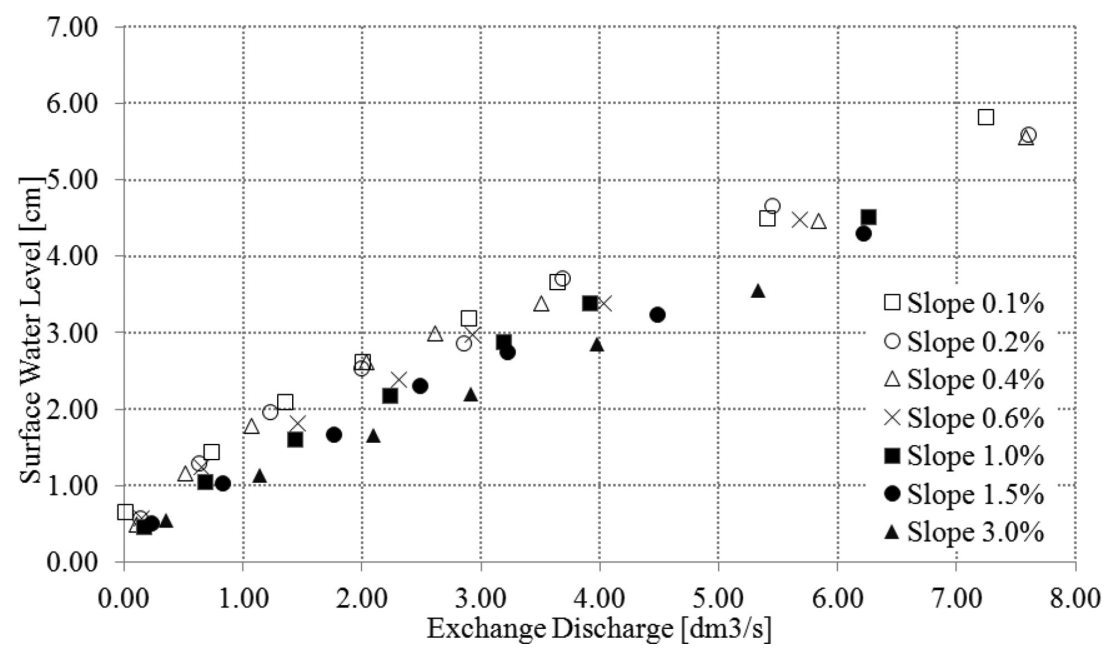

Figure 5: Measured exchange discharge and surface water level (in point SV1) for different surface slope values.

Orifice formula should be used when both upstream and downstream water levels $\left(h_{U}, h_{D}\right)$ are above crest elevation $\left(z_{\text {crest }}\right)$, Fig. 4 , and upstream water level above the crest $\left(h_{U}-z_{\text {crest }}\right)$ is more than $A_{m h} / w$ :

$$
Q=\operatorname{sign}\left[h_{m h}-h_{2 d}\right] c_{o} A_{m h} \sqrt{2 g}\left(h_{U}-h_{D}\right)^{1 / 2} .
$$

where $c_{o}$ stands for orifice discharge coefficient.

\subsection{Exchange model analyses and verification}

In relation to the type of measurements done, the focus in this paper is on free weir exchange formula (1), which corresponds to experimental scenarios. The equation is derived from a basic hydraulic formula for weir discharge which is a much more simple case than the interaction between surface flow and storm water sewage flow. Here the question arises if it is viable for the latter one.

What can be seen is that the formula (1) is completely devoid of surface flow dynamics elements such as surface flow velocity. While it can be neglected in standard weir equation usage because of relatively small values of velocity for urban area inundation we cannot make such assumptions. Our research shows that inflow discharge into an inlet is highly dependent on surface flow characteristics. In Fig. 5 we can see varying values of exchange discharge for similar surface water levels dependent on slope values. 
As we can see on graph, exchange discharge vary significantly between different slope values. Free weir equation described in this paper does not give us any way to implement the obtained information into calculations. The only influence on exchange discharge value comes from weir coefficient.

It was tested how well the relation between interaction flow and surface water level for different slopes can be represented by a formula if the coefficient would vary between them. That said, it was chosen by linear regression to best fit measurements data. In Table 2 we can see the estimated values of weir coefficients for different surface slopes. Figure 6 shows us how weir formula calculated discharges (with estimated coefficients) correspond to measured values; to make results more clear, just 3 slope values are presented on Fig. 6.

What can be seen is that with correct choice of coefficients free weir equation gives us valuable exchange discharge values for a considered scenario. While calculated and meas-

Table 2: Weir coefficients for different surface slope values.

\begin{tabular}{cc}
\hline Surface slope $(\%)$ & Approximated weir coefficient \\
\hline 0.1 & 0.37 \\
0.2 & 0.39 \\
0.4 & 0.41 \\
0.6 & 0.43 \\
1.0 & 0.46 \\
1.5 & 0.51 \\
3.0 & 0.59 \\
\hline
\end{tabular}

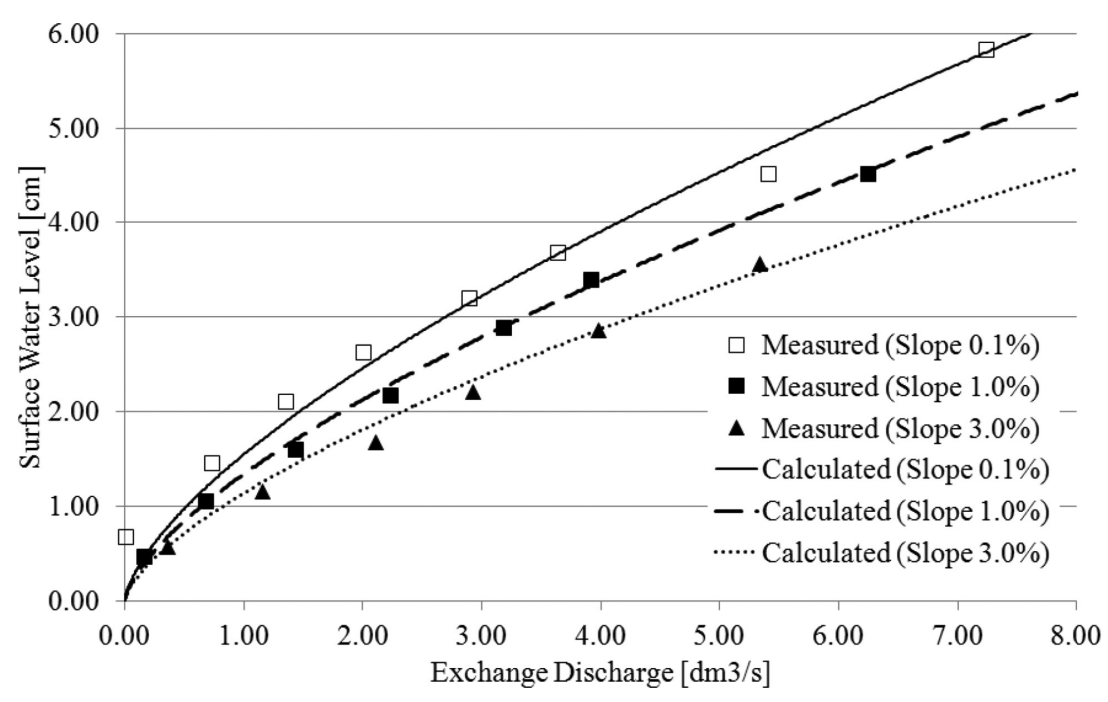

Figure 6: Comparison between measured exchange discharges and surface water level and calculated ones. 
ured discharges fit well the coefficient choice is hard to implement in practice. Its dependence on surface slope is significant enough that it needs to be varied for model to work correctly, but it can be assumed that it should be related to other, more flow-dependent variables.

Due to the said assumption, the next step of the study was to attempt to relate coefficient values to flow parameters such as surface flow velocity or Froude number. For analyzed scenarios, the best match was obtained for dependence on the Froude number, Fig. 7. In Fig. 7 we can see the dependence of weir coefficients calculated from measurements and Froude number in a cross-section $5 \mathrm{~cm}$ above the exchange structure for different slope values.

It can be noticed that the relation between both parameters is linear no matter what the surface slope and regardless of the flow being sub critical or supercritical. Due to this it can be assumed that some kind of relation between weir coefficient and Froude number can be derived:

$$
c_{F r}=a+b^{*} F r .
$$

where $c_{F r}$ is the new weir coefficient, $a$ and $b$ stand for the empirical coefficients and $F r$ for Froude number [-] at grid point from which surface water level is taken for exchange discharge calculation.

Crucial part of the proposed formula are empirical coefficients. From measurements we can conclude that its values can be set as constant for one interaction device. For used interaction structure they take sequentially values $a=0.089$ and $b=0.244$ [-]. In Fig. 7, we can also see how well proposed formula fit into measurement data.

Inaccuracies at the low and high end of Froude number range can be due to more problematic measurements with low water levels $(<1 \mathrm{~cm})$ and with greater velocities values that result in stronger disturbances of water surface. Those can also of course mean that relation changes its character for low and high values of Froude number. In Fig. 7 we can see that the described inaccuracies are not significant and further investigation is necessary to evaluate if they become more of an issue for even greater water velocities values.

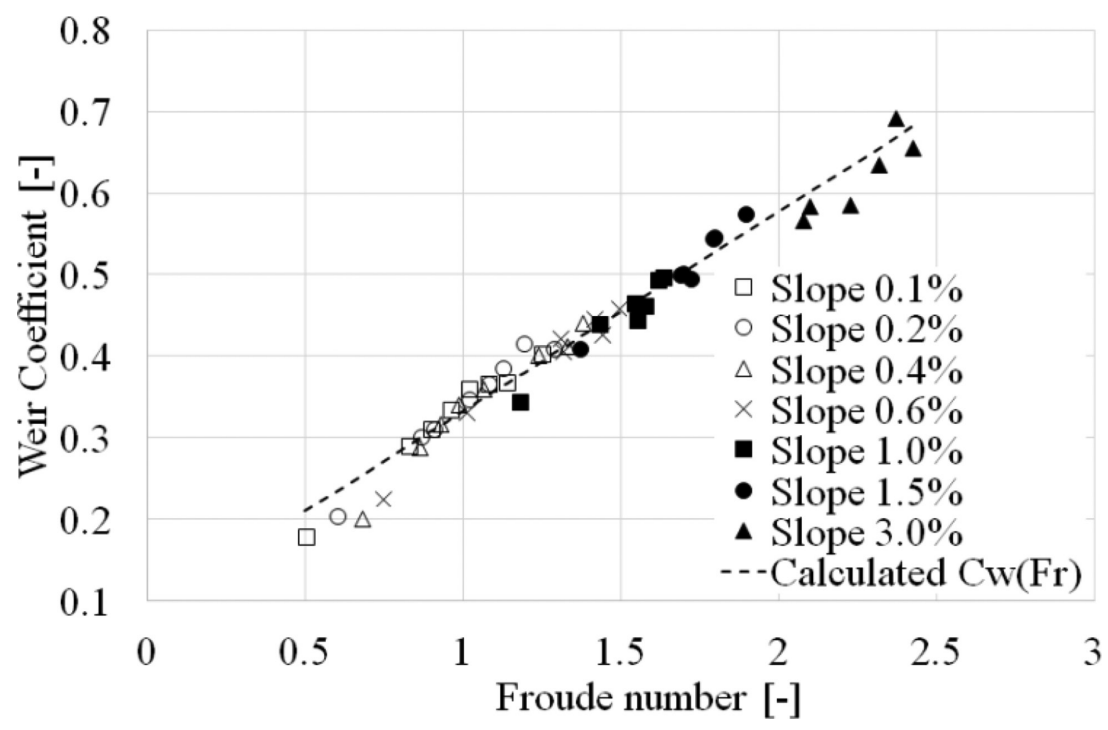

Figure 7: Relation between measured weir coefficients and Froude number with proposed $\mathrm{Cw}(\mathrm{Fr})$ formula. 


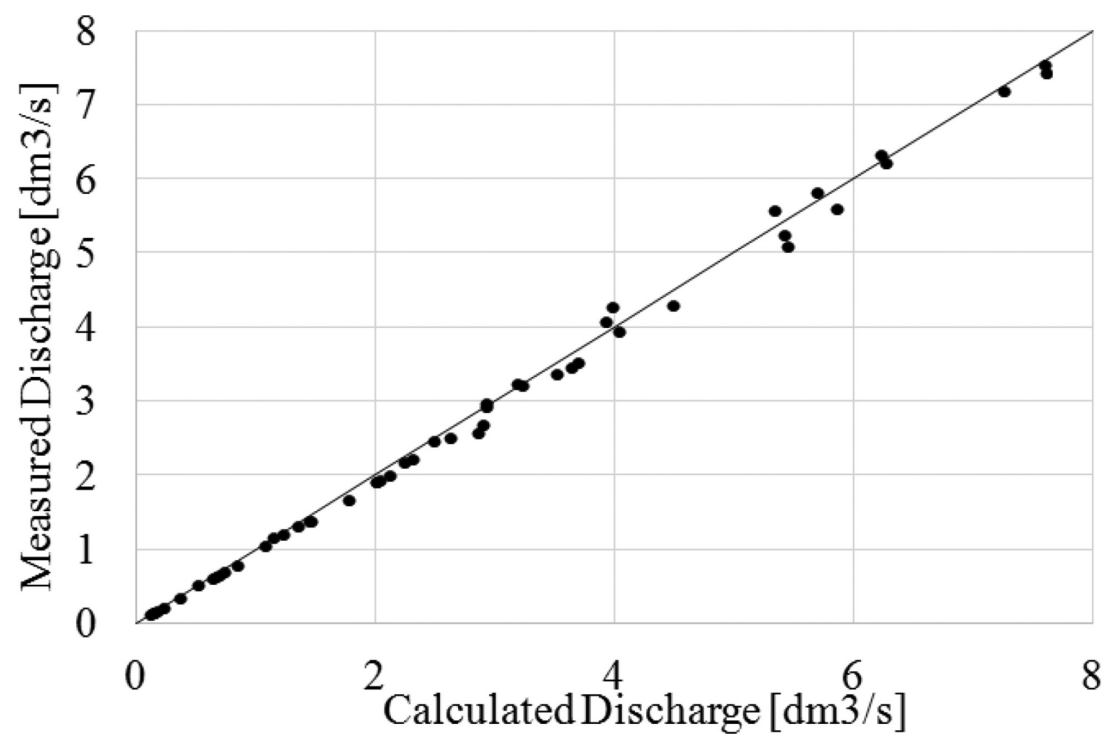

Figure 8: Comparison between measured and calculated values.

The above approach gets us to formulating the interaction formula for free weir inflow from surface into sewage, which includes surface flow conditions:

$$
Q=c_{F r} w \sqrt{2 g}\left(h_{s}-z_{\text {crest }}\right)^{3 / 2} .
$$

In Fig. 8 we can see the comparison between measured and calculated (with proposed formula) values of exchange discharge. Average absolute error value is $0.082 \mathrm{dm}^{3} / \mathrm{s}(4,23 \%)$ it is due to difference in higher discharges what can be connected to difficulties in accurate outflow measurements for high flow values at test stand.

As said in the introduction regarding the preliminary character of research, the proposed relation is just a basic approach that can be considered as the first step to further investigation. Especially, verification is needed to evaluate if formula and assumption of weir coefficient relation with Froude number are appropriate for different intake structures.

Looking at Fig. 8 we can tell that the used equation gives us valuable results for a tested case. As far as our research goes we can assume that in future it could be used in described in latter part of paper urban flood model.

\section{URBAN FLOOD INUNDATION MODEL}

Derived formulas of exchange between surface and sewage flow will be used in complex modelling of urban flooding. For that purpose, a numerical model was developed. It consists of three parts which are rainwater sewage flow model, surface flow model and interaction model described in this paper.

Storm sewage conduit flow can be described by the Saint-Venant equations [10]:

$$
\frac{\partial \mathbf{U}}{\partial t}+\frac{\partial \mathbf{F}}{\partial x}=\mathbf{S}
$$

where the vectors $\mathbf{U}, \mathbf{F}$ and $\mathbf{S}$ are given as:

$$
\mathbf{U}=\left(\begin{array}{l}
A \\
Q
\end{array}\right), \mathbf{F}=\left(\begin{array}{l}
Q \\
Q^{2} / A+I
\end{array}\right), \mathbf{S}=\left(\begin{array}{l}
0 \\
g A\left(S_{o}-S_{f}\right)
\end{array}\right) .
$$


where $x$ represents the distance along the sewer conduit, $t$ represents time, $A$ is the crosssectional wetted area, $Q$ is the flow discharge and $g$ is the gravitational acceleration. $I=p A / \rho$, where $p$ is the pressure at the centroid of $A$, and $\rho$ is the constant fluid density. For the hydrostatic pressure distribution, the term $I$ can be defined as $I=g A h_{c}$, where $h_{c}$ is the distance between the free surface and centroid of flow cross-sectional area. $S_{0}$ and $S_{\mathrm{f}}$ are the bottom and friction slopes, respectively. The friction slope can be defined by Manning formula.

In a developed model, these equations are solved using improved (TVD) McCormack scheme [11] of finite differences method (FDM) which is the explicit scheme that can capture sharp discontinuities that are common in rainwater sewage flow. To simulate transient flow and surcharge situation Preissmann slot idea is being use [12].

Solving surface flow in a described model is based on solving shallow water equations [Tan 1992]. To simplify calculations and to solve dry area flow the approximated approach of nonlinear diffusive wave equation was used:

$$
\frac{\partial H}{\partial t}+\frac{\partial}{\partial x}\left(K \frac{\partial H}{\partial x}\right)=0 .
$$

where $x$ is distance, $t$ is the time, $H$ is the water surface elevation above the assumed datum and $K$ is the coefficient of diffusion. $K$ is defined as:

$$
K=\frac{1}{n} h^{5 / 3}\left|\frac{\partial H}{\partial x}\right|^{-1 / 2} \text {. }
$$

where $n$ is Manning roughness coefficient and $h=H-Z$ which is the flow depth.

In the preliminary stage of research only $1 \mathrm{D}$ surface flow model is used. Equations (8) and (9) are being solved with modified Galerkin finite elements method (FEM) [6]. For the integration of ordinary differential equation over time, two level difference scheme is applied.

In further work, described model will be used for urban area inundation with usage of interaction equations described in this paper.

\section{CONCLUSIONS}

Experiments that were carried out allowed analysis and verification of formulas used for calculating exchange discharge between surface and rainwater sewage flow. All tests and further investigation were made for free inflow from surface into sewage which correspond to free weir condition, eqn. (1). This scenario can be observed mostly during the first phase of urban area inundation when heavy rainfall occurs and it is crucial for its further development.

Test results were used for verification of free weir formula which is widely used for calculating the interaction during described flow characteristics. The primary conclusion that can be drawn from the experiment results is the dependence of exchange discharge on surface flow parameters, which are not included in the formula. This can lead to severe errors when calculating interaction discharge for high surface velocities or high surface Froude number since used equations were not derived for such conditions.

In this paper, formula that makes weir coefficient dependent on surface flow condition was proposed. After test results analyzing optimal approach was chosen, eqn. (4), which links weir coefficient to Froude number on surface. The described approach can be used for complex urban area inundation modelling due to its simplicity. It gives us verified, good quality results for different surface geometry and flow conditions and requires only two constant coefficients that need to be empirically identified and most likely are unique for different intake structures and Froude number which can be easily calculated in most urban flooding surface flow models. 
It must be said that conclusions and test results are preliminary so it is correct to assume that the described equation can not be relevant for different interaction devices and different exchange directions. Due to this, further research on the matter is being done, which is focused on verification of formulas for various scenarios and intake structures. Those are planned to help developing exchange model that will be used in described in paper urban area inundation modelling tool.

\section{ACKNOWLEDGEMENT}

Research described in this paper is part of an ongoing research project "Stormwater and snowmelt runoff storage control and flash flood hazard forecasting in urbanized coastal basin" funded by the Provincial Fund for Environmental Protection and Water Management in Gdańsk.

\section{REFERENCES}

[1] Djordjević, S., Prodanovic, D., Maksimovic, C., Ivetic, M. \& Savić, D., SIPSON—simulation of interaction between pipe flow and surface overland flow in networks. Water Science and Technology, 52(5), pp. 275-283, 2005.

[2] Chen, A., Djordjević, S., Leandro, J. \& Savić, D., The urban inundation model with bidirectional flow interaction between 2D overland surface and 1D sewer networks. Proceedings NOVATECH 2007, 6th International Conference on Sustainable Techniques and Strategies in Urban Water Management, Lyon, 2007.

[3] Hakiel, J. \& Szydłowski, M., Interaction between storm water conduit flow and overland flow for numerical modelling of urban area inundation. GeoPlanet: Earth and Planetary Sciences: Hydrodynamic and Mass Transport at Freshwater Aquatic Interfaces, 2016.

[4] Szydłowski, M. \& Machalińska, J., Numerical simulation of transient flow in storm sewers using standard and improved McCormack scheme. Task Quarterly, 16(1), pp. 53-74, 2012.

[5] Szymkiewicz, R., Numerical Modeling in Open Channel Hydraulics, Springer: London, 2010.

http://dx.doi.org/10.1007/978-90-481-3674-2

[6] Gąsiorowski, D., Analysis of floodplain inundation using 2D nonlinear diffusive wave equation solved with splitting technique. Acta Geophysica, 61, pp. 668-689, 2013. http://dx.doi.org/10.2478/s11600-012-0087-8

[7] Nasello, C. \& Tucciarelli, T., Dual multilevel urban drainage Model. Journal of Hydraulic Engineering, 131, pp. 748-754, 2005.

http://dx.doi.org/10.1061/(ASCE)0733-9429(2005)131:9(748)

[8] Leandro, J., Djordjevic, S., Chen, A. \& Savic, D., The use of multiple-linking-element for connecting sewer and surface drainage networks. Proceeding, 32nd Congress of IAHR-Harmonizing the Demands of Art and Nature in Hydraulics, 2007.

[9] Gomez, M., Macchione, F. \& Russo, B., Methodologies to study the surface hydraulic behaviour of urban catchments during storm events. Water Science and Technology, 63(11), pp. 2666-2673, 2011. http://dx.doi.org/10.2166/wst.2011.174

[10] Cunge, J.A., Holly, F.M. \& Verwey, A., Practical Aspects of Computational River Hydraulics, London: Pitman Publishing Ltd., 1980. 
[11] Tseng, M.H., The improved surface gradient method for flows simulation in variable bed topography channel using tvd-maccormack scheme. International Journal for Numerical Methods Fluids, 43, pp. 71-91, 2003. http://dx.doi.org/10.1002/fld.605

[12] Szydłowski, M., Experimental verification of storm sewer transient flow simulation. Archives of Hydro-Engineering and Environmental Mechanics, 61(3-4), pp. 205-215, 2014.

http://dx.doi.org/10.1515/heem-2015-0014 